4-1-2016

\title{
Double-Stranded Water on Stepped Platinum Surfaces
}

\author{
Manuel J. Kolb \\ Rachael G. Farber \\ Loyola University Chicago \\ Jonathan Derouin \\ Loyola University Chicago \\ Cansin Badan \\ Federico Calle-Vallejo
}

See next page for additional authors

Follow this and additional works at: https://ecommons.luc.edu/chemistry_facpubs

Part of the Chemistry Commons

\section{Recommended Citation}

Kolb, Manuel J.; Farber, Rachael G.; Derouin, Jonathan; Badan, Cansin; Calle-Vallejo, Federico; Juurlink, Ludo B. F.; Killelea, Daniel; and Koper, Marc T. M.. Double-Stranded Water on Stepped Platinum Surfaces. Physical Review Letters, 116, 13: 136101-1 - 136101-5, 2016. Retrieved from Loyola eCommons, Chemistry: Faculty Publications and Other Works, http://dx.doi.org/10.1103/PhysRevLett.116.136101

This Article is brought to you for free and open access by the Faculty Publications and Other Works by Department at Loyola eCommons. It has been accepted for inclusion in Chemistry: Faculty Publications and Other Works by an authorized administrator of Loyola eCommons. For more information, please contact ecommons@luc.edu. cc) (i) $\Theta$

This work is licensed under a Creative Commons Attribution-Noncommercial-No Derivative Works 3.0 License. (c) American Physical Society, 2016. 


\section{Authors}

Manuel J. Kolb, Rachael G. Farber, Jonathan Derouin, Cansin Badan, Federico Calle-Vallejo, Ludo B. F. Juurlink, Daniel Killelea, and Marc T. M. Koper 


\title{
Double-Stranded Water on Stepped Platinum Surfaces
}

\author{
Manuel J. Kolb, ${ }^{1}$ Rachael G. Farber, ${ }^{2}$ Jonathan Derouin, ${ }^{2}$ Cansin Badan, ${ }^{1}$ Federico Calle-Vallejo, ${ }^{1}$ \\ Ludo B. F. Juurlink, ${ }^{1}$ Daniel R. Killelea, ${ }^{2}$ and Marc T. M. Koper ${ }^{1, *}$ \\ ${ }^{1}$ Leiden Institute of Chemistry, Leiden University, P.O. Box 9502, 2300 RA, Leiden, The Netherlands \\ ${ }^{2}$ Department of Chemistry and Biochemistry, Loyola University Chicago, \\ Chicago, Illinois 60660, USA
}

(Received 21 December 2015; published 29 March 2016)

\begin{abstract}
The interaction of platinum with water plays a key role in (electro)catalysis. Herein, we describe a combined theoretical and experimental study that resolves the preferred adsorption structure of water wetting the Pt(111)-step type with adjacent (111) terraces. Double stranded lines wet the step edge forming water tetragons with dissimilar hydrogen bonds within and between the lines. Our results qualitatively explain experimental observations of water desorption and impact our thinking of solvation at the $\mathrm{Pt}$ electrochemical interface.
\end{abstract}

DOI: 10.1103/PhysRevLett.116.136101

For many chemical reactions, metallic platinum is an excellent catalyst due to its moderate adsorption energies of reactants, intermediates, and products [1-4]. In aqueous electrochemical environments, competitive adsorption of the reactant and water, as well as the interaction of water with intermediates, influences reactivity [5]. It is not surprising that the interaction of water with models of $\mathrm{Pt}$ catalyst surfaces has attracted considerable interest, in particular, $\mathrm{Pt}(111)$ [6-10].

The complexity of the interaction of water with the $\mathrm{Pt}$ surface is exemplified by the first wetting layer. On $\mathrm{Pt}(111)$, water displays unique $\sqrt{37} \times \sqrt{37}$ or $\sqrt{39} \times \sqrt{39}$ networks $[7,11,12]$. However, realistic Pt catalysts are not well described using pristine $\mathrm{Pt}(111)$. Theoretical studies indicated that surface defects, e.g. steps, cause significant disruptions of extended water frameworks [13-17].

Experimentally, water has been studied on a wide range of planar metal systems [18-20]. An early scanning tunneling microscopy (STM) study investigated water adsorption on the two different step-edge types occurring on $\operatorname{Pt}(111)$ [21]. It was found that water preferred to form rows along these step edges. The exact nature of the adsorption structure was not resolved. In recent years, multiple theoretical studies have addressed water adsorption and solvation along platinum step edges [13-15,22]. In these studies, water was found to form one-dimensional (1D) lines along the step edge.

Recent, density functional theory (DFT) studies have explored the generality of 1D structures on Pt surfaces and how they evolve with water coverage [16,17]. For Pt(533), which contains four-atom-wide terraces and (100)-type step edges, increasing the number of water molecules within the unit cell, from one water molecule [23] to a higher number of molecules, initially leads to the formation of $1 \mathrm{D}$ lines at the upper edge [17]; this changes as the steps become saturated. Instead of lines, nearly isoenergetic two-dimensional (2D) structures of tetragons, pentagons, hexagons, and heptagons extending across the step onto the terrace are favored. These structures qualitatively explain the absence of a distinct water desorption feature from (111) terrace sites on $\mathrm{Pt}(533)$ [24]. Only a high-temperature desorption peak with a lowtemperature shoulder is observed for water coverages up to a monolayer. Alternatively, on the similar Pt(553) surface, with five-atom-wide terraces separated by (111) steps, two distinct desorption features are observed, a Pt(533)-like high-temperature desorption peak and a desorption peak very similar to that found on $\operatorname{Pt}(111)$ [25]. The pronounced differences between such similar surfaces suggest that the structure of adsorbed water depends critically on the atomic geometry of the steps.

In this work, we combined DFT calculations and lowtemperature STM to resolve the structure of water adsorbed to the (111)-step type disrupting $\mathrm{Pt}(111)$ planes. In contrast to the (100)-step type, we found a single most favorable structure. It is a new adsorption geometry consisting of two parallel 1D water strands aligned to form 2D water tetragons. The details of the structure qualitatively explain the distinct desorption of step-bound and terrace-bound water. In addition, this most favorable structure affects our thinking of the solvation environment in Pt electrocatalysis.

The DFT calculations were performed with the VASP code [26], projected augmented wave projectors [27], and the Perdew-Burke-Ernzerhof functional [28]. The computational settings used in this study have been described elsewhere [17,23]. All adsorption energies were calculated as mean Gibbs energies per water molecule at $100 \mathrm{~K}$,

$$
\Delta G_{\text {tot }, n \mathrm{H}_{2} \mathrm{O}}=\frac{G_{\text {total }, n \mathrm{H}_{2} \mathrm{O}}-G_{\text {clean }}-n G_{\mathrm{H}_{2} \mathrm{O}(g)}}{n},
$$

where the individual $G$ 's were estimated as 


$$
G_{\text {tot }, n \mathrm{H}_{2} \mathrm{O}}=E_{\mathrm{DFT}, n \mathrm{H}_{2} \mathrm{O}}+Z P E_{n \mathrm{H}_{2} \mathrm{O}}-T S_{\left(n \mathrm{H}_{2} \mathrm{O}\right), \text { vib }}
$$

for the surface-adsorbed species and

$$
G_{\mathrm{tot}, \mathrm{H}_{2} \mathrm{O}(g)}=E_{\mathrm{DFT}, \mathrm{H}_{2} \mathrm{O}}+Z P E_{\mathrm{H}_{2} \mathrm{O}}-T S_{\mathrm{H}_{2} \mathrm{O}, \text { tot }}
$$

for gas phase $\mathrm{H}_{2} \mathrm{O}$. The values for $S_{\mathrm{H}_{2} \mathrm{O} \text {,tot }}$ appear in Ref. [29]. The Zero Point Energy (ZPE) and vibrational entropy corrections were found to be very similar across all water structures, with an average $\mathrm{ZPE}$ per $\mathrm{H}_{2} \mathrm{O}$ of $0.666 \mathrm{eV}$ and a standard deviation of $0.0044 \mathrm{eV}$. The average vibrational entropy correction at $100 \mathrm{~K}$ was found to be $0.040 \mathrm{eV}$ per $\mathrm{H}_{2} \mathrm{O}$ with a standard deviation of $0.0033 \mathrm{eV}$. STM simulations based upon the DFT charge densities were performed using the program HIVE by Vanpoucke and Brocks [30]. Tip smoothening, as implemented in this software, was used with a tip size of $0.75 \AA$ [31].

Experiments in Chicago were performed in an ultrahigh-vacuum (UHV) system comprised of a preparatory chamber and STM chamber [32,33]. The Pt(553) surface (Surface Preparation Laboratory, Zaandam, Netherlands) was cleaned following published procedures [34]. Surface cleanliness was confirmed via Auger electron spectroscopy and the presence of a sharp low-energy electron diffraction pattern [25]. A directed doser was used to minimize background contamination while exposing the Pt crystal to $\mathrm{D}_{2} \mathrm{O}$. $\mathrm{D}_{2} \mathrm{O}$ was used rather than $\mathrm{H}_{2} \mathrm{O}$ due to the lower background of $\mathrm{D}_{2} \mathrm{O}$ in the UHV chamber. The $\operatorname{Pt}(553)$ surface was dosed at $T_{s}=100 \mathrm{~K}$ with the directed doser $1 \mathrm{~cm}$ from the crystal face. After exposure, the crystal was annealed at $160 \mathrm{~K}$. Temperature programmed desorption (TPD) spectra were taken with a ramp rate of $1 \mathrm{~K} \mathrm{~s}^{-1}$. Prior to imaging, the sample was flashed to $175 \mathrm{~K}$. TPD experiments in Leiden were performed on the same Pt sample using an UHV system with a differentially pumped quadrupole mass spectrometer (QMS, Baltzers QMA 400). Water was dosed from a directional doser, and TPD experiments were performed at a distance between the crystal and the QMS orifice of $2 \mathrm{~mm}$ and the same heating rate as in Chicago.

In the following, we show the most stable water adsorption structures obtained with DFT as the coverage along the step edge increases. A full account of all modeled structures is available in the Supplemental Material [35]. At low coverages, our 1D zigzag structure was in agreement with previously reported results $[13,14]$. The adsorption energy was $-0.322 \mathrm{eV} / \mathrm{H}_{2} \mathrm{O}$ [Fig. 1(a)]. At larger coverages, water formed isolated closed-ring structures that maximized the number of hydrogen bonds [Fig. 1(b)]. There was a distinct preference for tetragonal adsorption structures. The adsorption energy of $-0.362 \mathrm{eV} / \mathrm{H}_{2} \mathrm{O}$ was $0.028 \mathrm{eV} / \mathrm{H}_{2} \mathrm{O}$, more stable than any other structures at similar coverages.

The formation of tetragonal networks was also preferred at coverages which allow for the formation of fully closed

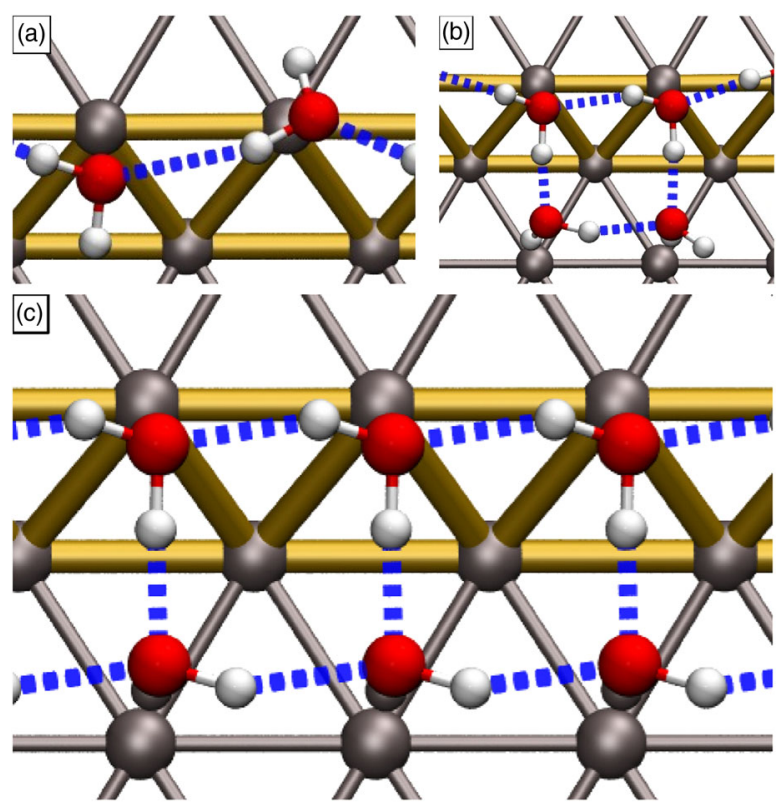

FIG. 1. Top views of the most favorable adsorption structures for increasing coverage: (a) zigzag structure, (b) isolated tetragon, and (c) double stranded, tetragonal 4-4-4 structure towards the lower terrace. Platinum atoms appear in silver, oxygen in red, hydrogen in white, and the (111) step edge is marked in yellow.

ring structures along the step edge [Fig. 1(c)]. The adsorption energy was $-0.441 \mathrm{eV} / \mathrm{H}_{2} \mathrm{O}$. Any other adsorption structure yielded an energy that was at least $0.013 \mathrm{eV} / \mathrm{H}_{2} \mathrm{O}$ less favorable. The most likely cause for this exceptional adsorption energy was the underlying geometry of the (111) step edge of $\operatorname{Pt}(553)$. In the upper strand, water molecules were adsorbed atop the sevenfold coordinated platinum atoms. In the lower strand, water molecules adsorbed atop the nearest ninefold coordinated Pt atoms. The rectangular geometry of the involved Pt atoms caused hydrogen bonds to be directed both along and orthogonal to the step edge. The former caused the $1 \mathrm{D}$ lines, whereas the latter caused two lines to form a double stranded structure. All water molecules making up the lower strand were oriented $\mathrm{H}$ down, while all water molecules adsorbed on the upper edge were adsorbed flat atop the edge Pt atoms.

We previously used the Smoluchowski effect to rationalize the geometric configuration of water on $\mathrm{Pt}(533)$ [17]. The same holds true for the (111) step edge of Pt(553). This effect consists of a charge separation at steps: a positive partial charge at the upper step edge is balanced by a negative partial charge on the lower edge. Water molecules on the upper edge interact with the positive $\mathrm{Pt}$ atoms by adsorbing through the oxygen atom. On the lower edge and the terrace, water orients $\mathrm{H}$ down to maximize the interaction between the negative partial charge of the Pt and the positive charge of the hydrogen atom.

In conclusion, a strong templating effect of the (111)type step edge on $\operatorname{Pt}(553)$ creates the double-stranded water 


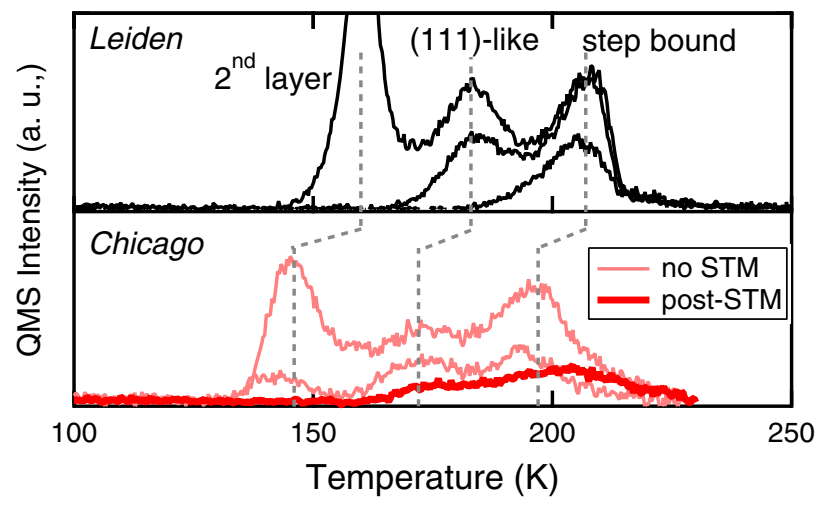

FIG. 2. TPD spectra of water desorbing from Pt(553).

structure along the step edge. The geometric orientation can be rationalized by the Smoluchowski effect.

The TPD spectra in Fig. 2 show three separate peaks for water desorption from $\mathrm{Pt}(553)$. In order of increasing desorption temperature, these distinct features correspond to desorption from multilayers, (111) terraces, and step edges. Results from both laboratories were in line with those previously reported on planar and stepped $\mathrm{Pt}$ surfaces [25,36]. Slight differences in peak desorption temperatures $(<10 \mathrm{~K})$ were attributed to differences in temperature measurement. Submonolayer water coverages for STM imaging on the $\mathrm{Pt}(553)$ sample were obtained by annealing to $175 \mathrm{~K}$ after $\mathrm{D}_{2} \mathrm{O}$ exposure. This removed multilayer and most of the terrace-bound water. The postSTM TPD trace in Fig. 2 shows that desorption from the step edges was predominant even after prolonged time in the STM (4 times longer than necessary to obtain the images), with negligible accumulation of background gases, confirming that water mostly remained on the step edges with some terrace-bound water desorption following imaging. No evidence of the dissociation of water was observed; the high-temperature peak at $270 \mathrm{~K}$ [37] indicating $O H_{\text {ads,step }}$ was absent. Furthermore, no isotope scrambling was observed, with the main desorption feature stemming from $m / z=20\left(\mathrm{D}_{2} \mathrm{O}^{+}\right)$and its daughter fragment at $m / z=18\left(\mathrm{OD}^{+}\right)$.

In Fig. 3(a), we show a STM image of clean Pt(553) with the surface composed of regularly sized terraces, about $1.35 \mathrm{~nm}$ wide, with crisp step edges. The terraces were mostly five-atom-wide (111) facets separated by one-atomhigh (111) steps, with around 10\% being either four- or sixatoms wide. In contrast, after water deposition, the surface corrugation decreased, and bright lines were evident along the step edges, as seen in Fig. 3(b). Imaging conditions were modeled after previous work to limit water perturbation [6,38]. Tunneling currents below $10 \mathrm{pA}$ revealed that the bright features lie along the step edges [Fig. 3(b)] [38]. The water molecules appeared to arrange in two parallel strands, one line atop the step edge and the second just below, forming the bright step-edge decorations. Some water molecules appeared in between the strands. This was
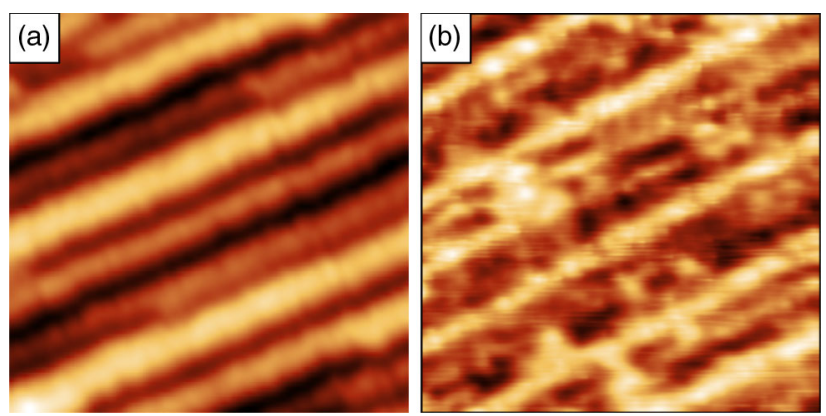

FIG. 3. (a) STM image of the clean $\mathrm{Pt}(553)$ surface. $V=1 \mathrm{~V}$, $I=200 \mathrm{pA}, T_{\mathrm{STM}}=25 \mathrm{~K}, 8 \times 8 \mathrm{~nm}^{2}$. (b) STM image of the water-covered surface. $V=-0.90 \mathrm{~V}, I=-9 \mathrm{pA}, T_{\mathrm{STM}}=25 \mathrm{~K}$, $8 \times 8 \mathrm{~nm}^{2}$.

in line with some desorption occurring at $\sim 170 \mathrm{~K}$ from terrace sites in the TPD spectrum.

Figure 4(a) shows a representative STM image of adsorbed water on $\mathrm{Pt}(553)$. The primary features of this
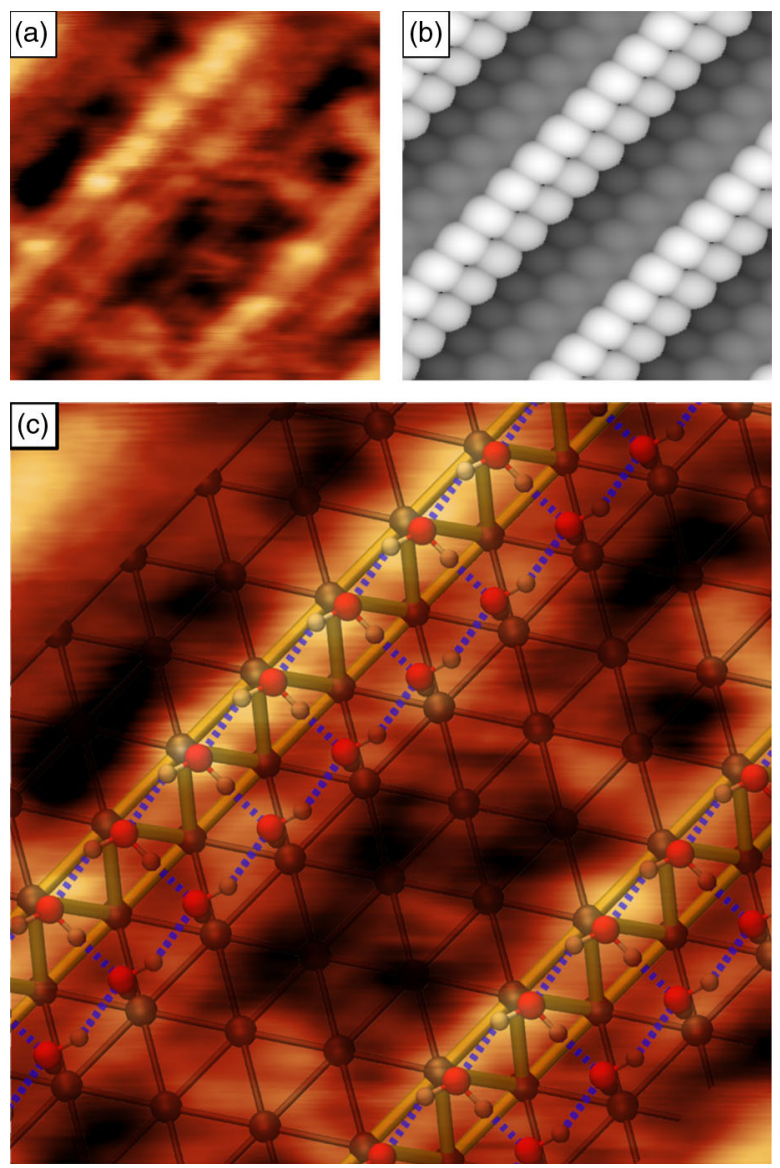

FIG. 4. (a) STM image of $\mathrm{D}_{2} \mathrm{O}$-covered step edges on $\mathrm{Pt}(553)$. $V=-1 \mathrm{~V}, \quad I=-9 \mathrm{pA}, \quad T_{\mathrm{STM}}=25 \mathrm{~K}, \quad 4.5 \mathrm{~nm} \times 4.5 \mathrm{~nm}$. (b) STM simulation of water adsorbed on $\operatorname{Pt}(553)$, bright areas are oxygen atoms of water, darker areas are located at Pt terraces, $V=-0.9 \mathrm{~V}$. (c) Overlay of atomic positions of DFT and STM imaging, $V=-1 \mathrm{~V}, I=-9 \mathrm{pA}, T_{\mathrm{STM}}=25 \mathrm{~K}$, $4.5 \times 4.5 \mathrm{~nm}^{2}$. 
image are the periodic, parallel strands of water molecules described above. Based upon the energetically most favorable double stranded tetragonal 4-4-4 structure [see Fig. 1(c)], we performed simulations of STM images, which are shown in Fig. 4(b). The bright stripes in the simulated image corresponding to the oxygen atoms of water are in good agreement with the actual STM image. Figure 4(c) shows the overlay of the calculated periodic double stranded structure onto the image in Fig. 4(a). The image based on the DFT geometry was scaled so that the step-edge structures in the STM overlap with the periodically repeated step edges in the DFT data. Lattice size and water position on the step edges were consistent across multiple STM images, supporting the double-stranded water structure along the $\operatorname{Pt}(553)$ step edges. To exclude possible bias, we considered other possible structures with the next-best adsorption energies per water molecule. We found that these structures did not reproduce the parallel lines observed in the STM images. Additional details on this topic can be found in the Supplemental Material [35].

In summary, we have demonstrated in this Letter a unique water structure that exists along the $\operatorname{Pt}(553)$ step edge. DFT calculations predicted the formation of double stranded networks that are connected to form tetragonal structures along the step edge, due to the templating effect of the underlying step geometry. This templating effect of the (110) step site distinguishes it from the (100) step, where no such templating effect was observed [17]. Experimental STM images found two parallel lines of water molecules along the step edge, and verified the templating effect, confirming the formation of doublestranded water structures. These results highlight the tremendous effect the electronic corrugation of the stepped Pt surface had on the structures of adsorbed water. Double stranded configurations of water had neither been theoretically nor experimentally reported until now. Furthermore, our results suggest that the 1D line is unlikely to be a good representation of a full solvation environment at step edges. Instead, the observed, strongly bound, 2D structures cover the steps. Accurate assessments of solvation must take these structures into account and are necessary for the determination of surface phase diagrams of actual platinum catalysts.

We acknowledge financial support from the Netherlands Organization for Scientific Research (NWO) as a TOP grant awarded to L. B. F. J. and M. T. M. K. and as a VENI grant awarded to F. C. V., Project No. 722.014.009. We thank the Nationale Computerfaciliteiten (NCF) for $\mathrm{CPU}$ time. R. G. F., J. D., and D. R. K. would like to acknowledge the donors of the American Chemical Society Petroleum Research Fund for partial support of this research through Grant No. PRF 54770-DNI5. J. D. would also like to acknowledge the Arthur J. Schmitt Foundation for support. *m.koper@chem.leidenuniv.nl

[1] J. Greeley, T. F. Jaramillo, J. Bonde, I. Chorkendorff, and J. K. Norskøv, Nat. Mater. 5, 909 (2006).

[2] I. E. L. Stephens, A. S. Bondarenko, U. Gronbjerg, J. Rossmeisl, and I. Chorkendorff, Energy Environ. Sci. 5, 6744 (2012).

[3] F. Calle-Vallejo, J. Tymoczko, V. Colic, Q. H. Vu, M. D. Pohl, K. Morgenstern, D. Loffreda, P. Sautet, W. Schuhmann, and A. S. Bandarenka, Science 350, 185 (2015).

[4] H. Li, Y. Li, M. T. M. Koper, and F. Calle-Vallejo, J. Am. Chem. Soc. 136, 15694 (2014).

[5] Y. Sha, T. H. Yu, Y. Liu, B. V. Merinov, and W. A. Goddard, J. Phys. Chem. Lett. 1, 856 (2010).

[6] S. Maier, I. Stass, J. I. Cerdá, and M. Salmeron, Phys. Rev. Lett. 112, 126101 (2014).

[7] S. Standop, A. Redinger, M. Morgenstern, T. Michely, and C. Busse, Phys. Rev. B 82, 161412 (2010).

[8] S. Sakong, M. Naderian, K. Mathew, R. G. Hennig, and A. Gross, J. Chem. Phys. 142, 234107 (2015).

[9] V. Tripković, E. Skúlason, S. Siahrostami, J. K. Nørskov, and J. Rossmeisl, Electrochim. Acta 55, 7975 (2010).

[10] E. Skulason, G. S. Karlberg, J. Rossmeisl, T. Bligaard, J. Greeley, H. Jonsson, and J. K. Nørskov, Phys. Chem. Chem. Phys. 9, 3241 (2007).

[11] P. J. Feibelman, N. C. Bartelt, S. Nie, and K. Thrmer, J. Chem. Phys. 133, 154703 (2010).

[12] G. Zimbitas, S. Haq, and A. Hodgson, J. Chem. Phys. 123, 174701 (2005).

[13] S. Meng, E. G. Wang, and S. Gao, Phys. Rev. B 69, 195404 (2004).

[14] L. Arnadottir, E. M. Stuve, and H. Jonsson, Surf. Sci. 604, 1978 (2010).

[15] R. Peköz, S. Wörner, L. M. Ghiringhelli, and D. Donadio, J. Phys. Chem. C 118, 29990 (2014).

[16] R. Jinnouchi, K. Kodama, and Y. Morimoto, J. Electroanal. Chem. 716, 31 (2014).

[17] M. J. Kolb, J. Wermink, F. Calle-Vallejo, L. B. F. Juurlink, and M. T. M. Koper, Phys. Chem. Chem. Phys. 18, 3416 (2016).

[18] M. Tatarkhanov, D. F. Ogletree, F. Rose, T. Mitsui, E. Fomin, S. Maier, M. Rose, J. I. Cerd, and M. Salmeron, J. Am. Chem. Soc. 131, 18425 (2009).

[19] K. Morgenstern and K.-H. Rieder, Chem. Phys. Lett. 358, 250 (2002).

[20] M. Mehlhorn, S. Schnur, A. Gross, and K. Morgenstern, ChemElectroChem 1, 431 (2013).

[21] M. Morgenstern, T. Michely, and G. Comsa, Phys. Rev. Lett. 77, 703 (1996).

[22] O. Endo, M. Nakamura, R. Sumii, and K. Amemiya, J. Phys. Chem. C 116, 13980 (2012).

[23] M. J. Kolb, F. Calle-Vallejo, L. B. F. Juurlink, and M. T. M. Koper, J. Chem. Phys. 140, 134708 (2014).

[24] A. den Dunnen, M. J. T. C. van der Niet, C. Badan, M. T. M. Koper, and L. B. F. Juurlink, Phys. Chem. Chem. Phys. 17, 8530 (2015).

[25] M. J. T. C. van der Niet, A. den Dunnen, L. B. F. Juurlink, and M. T. M. Koper, J. Chem. Phys. 132, 174705 (2010).

[26] G. Kresse and J. Furthmüller, Comput. Mater. Sci. 6, 15 (1996). 
[27] G. Kresse and D. Joubert, Phys. Rev. B 59, 1758 (1999).

[28] J. P. Perdew, K. Burke, and M. Ernzerhof, Phys. Rev. Lett. 77, 3865 (1996).

[29] M. W. Chase, C. A. Davies, J. R. Downey, D. J. Frirup, R. A. MacDonald, and A. N. Syverud, JANAF Thermochemical Tables, J. Phys. Chem. Ref. Data Vol. 14 (American Chemical Society and The American Institute of Physics, Washington, D.C., College Park, 1985).

[30] D. E. P. Vanpoucke and G. Brocks, Phys. Rev. B 77, 241308 (2008).

[31] D. E. P. Vanpoucke, Ph.D. thesis, University of Twente, 2009, ISBN:.

[32] J. Derouin, R. G. Farber, S. L. Heslop, and D. R. Killelea, Surf. Sci. 641, L1 (2015).
[33] J. Derouin, R. G. Farber, and D. R. Killelea, J. Phys. Chem. C 119, 14748 (2015).

[34] M. J. T. C. van der Niet, A. den Dunnen, L. B. F. Juurlink, and M. T. M. Koper, Phys. Chem. Chem. Phys. 13, 1629 (2011).

[35] See the Supplemental Material at http://link.aps.org/ supplemental/10.1103/PhysRevLett.116.136101 for a full list of adsorption geometries and their related energies and a data package containing all initial and final system coordinates.

[36] G. B. Fisher and J. L. Gland, Surf. Sci. 94, 446 (1980).

[37] M. J. T. C. van der Niet, O. T. Berg, L. B. F. Juurlink, and M. T. M. Koper, J. Phys. Chem. C 114, 18953 (2010).

[38] S. Nie, P. J. Feibelman, N. C. Bartelt, and K. Thürmer, Phys. Rev. Lett. 105, 026102 (2010). 